\title{
The Construction History and Assessment of Two Heritage Industrial Buildings in Wrocław
}

\author{
Piotr Berkowski*, Grzegorz Dmochowski, Jacek Barański, and Jerzy Szołomicki
}

Faculty of Civil Engineering, Wroclaw University of Science and Technology, Wyb. Wyspiańskiego 27, 50-370 Wrocław, Poland

\begin{abstract}
Industrial buildings from the beginning of the $20^{\text {th }}$ century can still be found in Polish cities. Some of them have already been listed as heritage objects. Those structures where new technical solutions and materials were used, for example concrete, are especially interesting. Some of those objects are currently under a process of restoration with the aim to reconstruct and adapt them for completely new and different utility functions but without losing their important heritage value. In this paper, elements of the assessment procedure of the technical state regarding a historical survey, material examination and structural analysis, are presented on the example of two selected industrial buildings in which reinforced concrete was used as the main structural material. The main aim of the performed diagnostic procedure was verification of the load-bearing capacity of structures of the examined buildings. The calculation made confirmed that in case of not damaged concrete elements they have enough capacity to carry on newly designed loads. That confirmed that old concrete structures, especially in industrial buildings, sometimes have capacity reserves. On the other hand it allows to perform the design of less invasive renovation works or strengthening solutions with the aim to respect their industrial heritage value.
\end{abstract}

\section{Introduction}

Industrial buildings from the beginning of the $20^{\text {th }}$ century, which have already been listed as heritage objects, can still be found in some Polish cities [1, 2, 3]. Those where new technical solutions and materials were used are especially interesting. Some of these buildings are currently under a process of restoration with the aim to reconstruct and adapt them for completely new and different utility functions, while not losing their important heritage value.

Historic concrete structures in many European countries, which are nowadays encountered during restoration works in public or industrial buildings, were constructed at the turn of the $20^{\text {th }}$ century $[1,2,3,4,5,6,7]$. In those times, construction and design codes were not yet established (until the early 1900s in France), however, many structural and material innovations came into use at that time. When such old structures need to be assessed for restoration or refurbishment works with regard to their structural integrity and

\footnotetext{
* Corresponding author: piotr.berkowski@pwr.edu.pl
} 
durability, it is important to know what to look for and how to identify the potential risks $[1,6]$ of both design and construction works. One extremely important element for a proper diagnosis of the current technical condition of such industrial heritage buildings is the results of their architectural and structural historical analysis. It is also essential for the adequate design of the process of their refurbishment or for the actions associated with prolonging the time of their use and the processes associated with their future maintenance. Such analyses must be related, among others, to the following aspects, which are taken into account during the design and construction of those objects: the design solutions, the calculation methods of structural analysis, the methods of the designing of structural components, the properties of building materials and technologies of their production, and also the technology of construction, including the quality of workmanship $[1,2,3]$.

In the following chapters, on the example of two old reinforced concrete industrial buildings, some results of the assessment of their technical condition are presented. The aim of the performed diagnostic procedure was to evaluate the possibility of adaptation of these buildings to new service functions.

\section{General description of the presented bakery buildings}

The entire bakery complex was constructed in several stages during the turn of the $20^{\text {th }}$ century and remained in service until 2006 [8]. It consisted of several buildings, each with a different structural shape and made of different construction materials: ranging from typical brick masonry to steel skeletal structures and monolithic concrete structures which were new for the time of their construction. In two of the industrial buildings - a flour warehouse and a connecting building - reinforced concrete was used as the main structural material.

\subsection{The flour warehouse building}

The multistory flour warehouse (Figs. 1, 2) is designed on a rectangular plan (ca. 19.0x $47.0 \mathrm{~m}$ ) and was used both for production and office functions. The building has 8 levels above the ground and does not have a basement. The external structure of the building is made of masonry (walls), however, for the main bearing structure, reinforced concrete was used - pillars, ribbed slabs (Fig. 3) and frames on two attic floors (Fig. 4). The baking process was also carried out here, despite it being used as a flour warehouse.

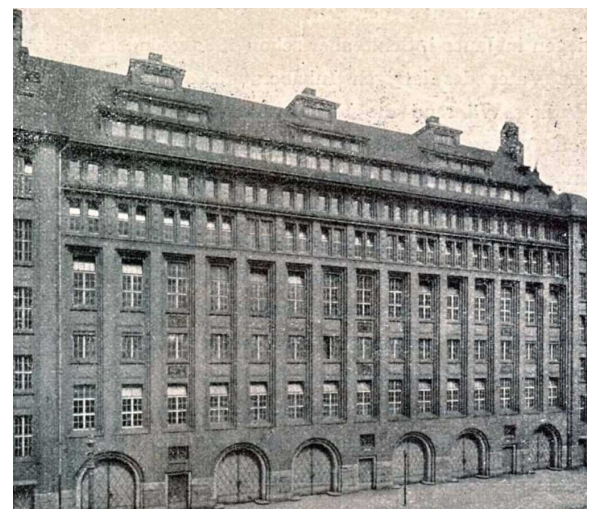

Fig. 1. The historical view of the flour warehouse.

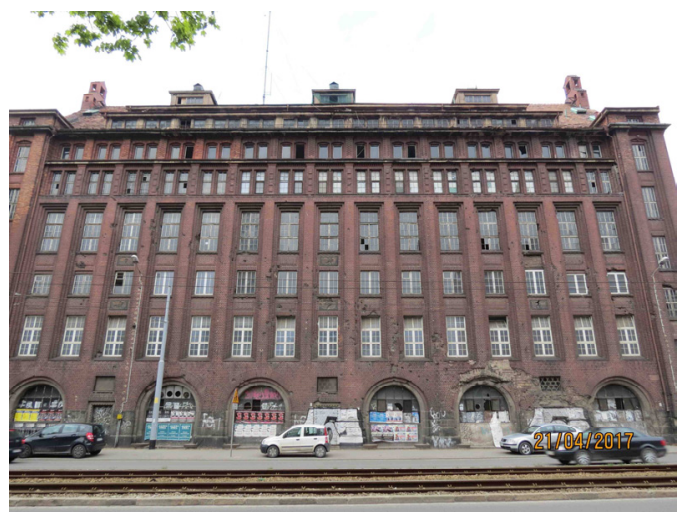

Fig. 2. The current view of the flour warehouse building. 


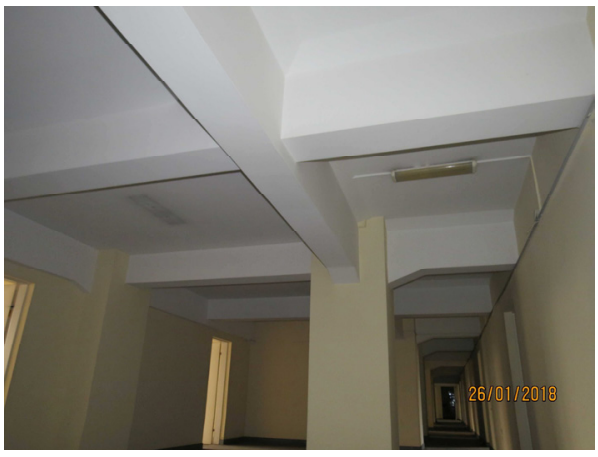

Fig. 3. The system of the RC beams and ribbed slab in the flour warehouse.

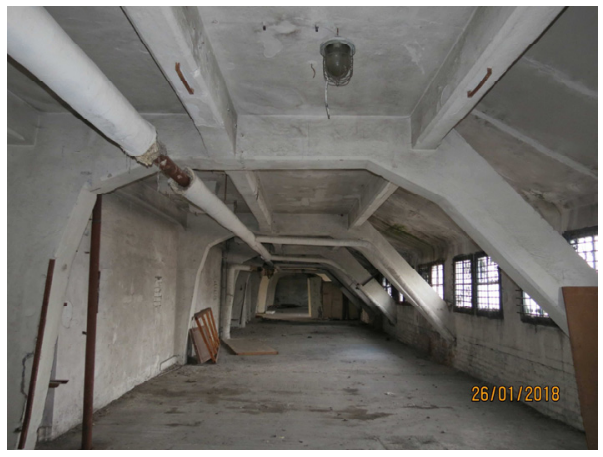

Fig. 4. The RC frame on the attic floors in the flour warehouse.

\subsection{The connecting building}

The connecting building (Figs. 5, 6) served as a link between the main building (the flour warehouse), which was built at the same time from its southern side, and the bakery buildings located from the north. The building is designed on a plan similar to a rectangle measuring 2.4x19.6 m. The building has 6 levels above ground (a ground floor, 5 upper floors and an attic).

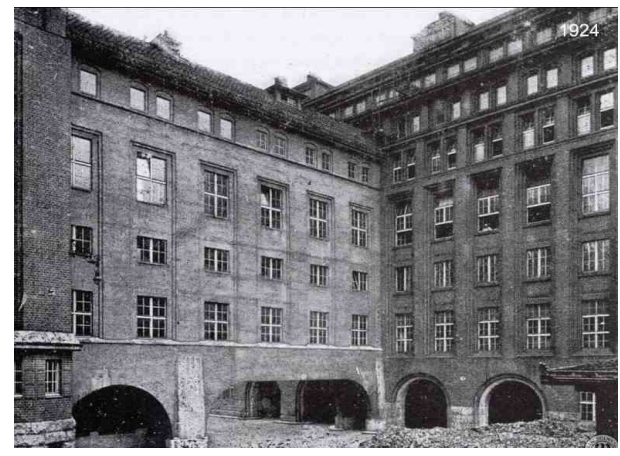

Fig. 5. The archival view of the connecting building [11].

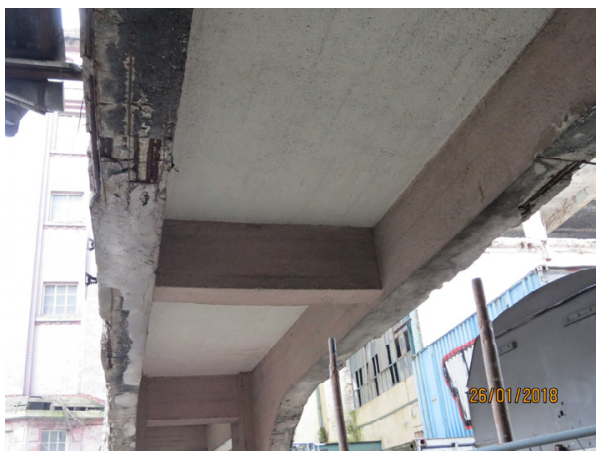

Fig. 7. The RC ground floor structure in the connecting building.

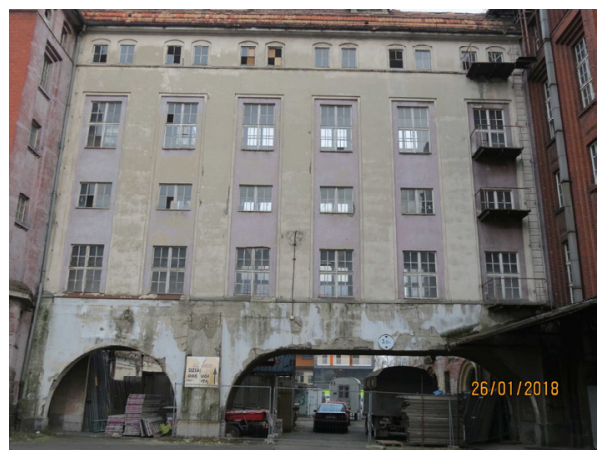

Fig. 6. The current view of the connecting building.

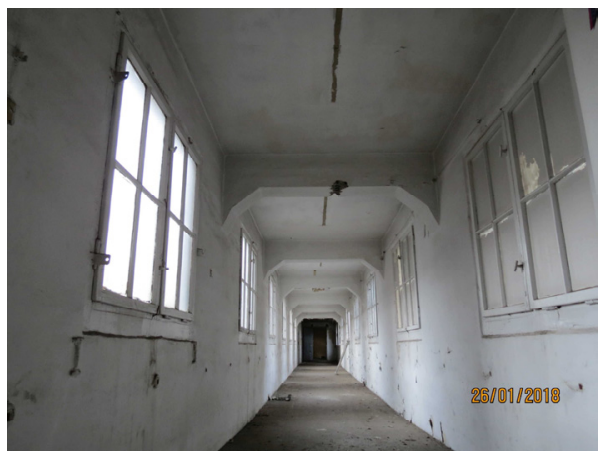

Fig. 8. The RC frames in the connecting building. 
On the ground level the main supporting structure was made in the form of two doublespan, arched reinforced concrete frames, which were based on the reinforced concrete pillars (Figs. 6,7) due to the need to maintain an open communication space. Above the ground level, the structure of the building is one-bay and is also made of reinforced concrete with load-bearing longitudinal walls that are strengthened with pilasters that are connected to beams. They work as a stiffening structure (Fig. 8).

\section{Selected elements of the structural condition assessment}

\subsection{Archival structural survey}

From the survey of the archived, historical documentation [12] and modern examination on site, it was identified that the foundation of the building was placed on 21 reinforced concrete wells (Figs. 9, 10) due to very difficult geotechnical conditions and a very high groundwater level. From the archival drawings, the authors concluded that the foundations of the wells were located $0.6 \mathrm{~m}$ above the ground water level at a depth of about $5.0 \mathrm{~m}$ below the terrain level. The wells are $4.0 \mathrm{~m}$ in height and the largest of them have a diameter of $6.4 \mathrm{~m}$.

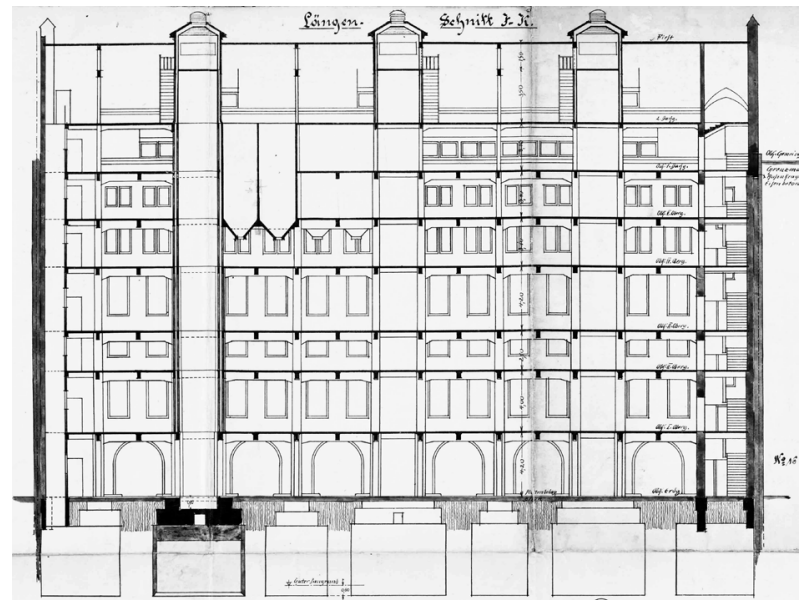

Fig. 9. The archival cross-section of the flour warehouse building [12].

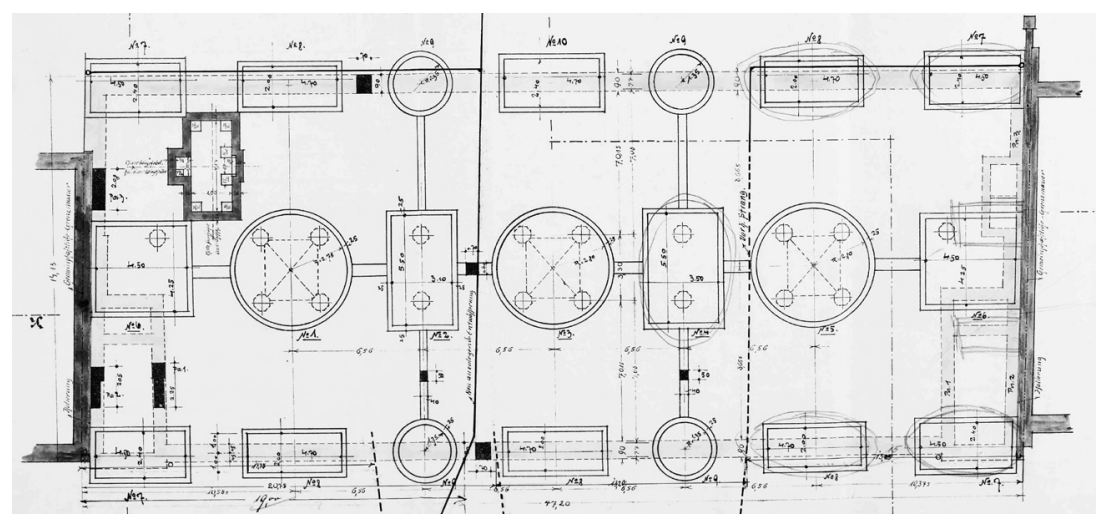

Fig. 10. The disposition of the foundation wells of the flour warehouse building [12]. 


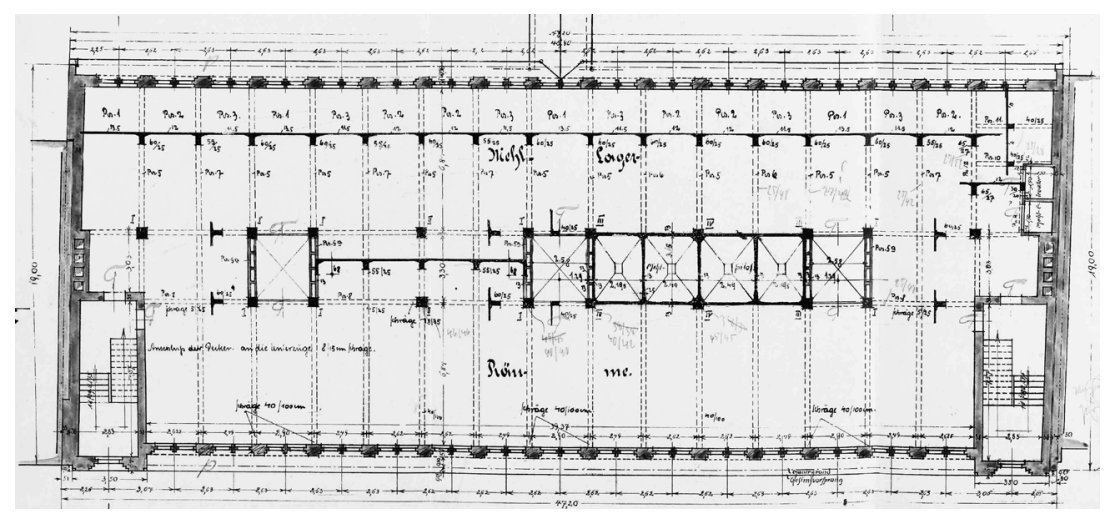

Fig. 11. The scheme of the RC slab on the $2^{\text {nd }}$ floor of the flour warehouse building [12].

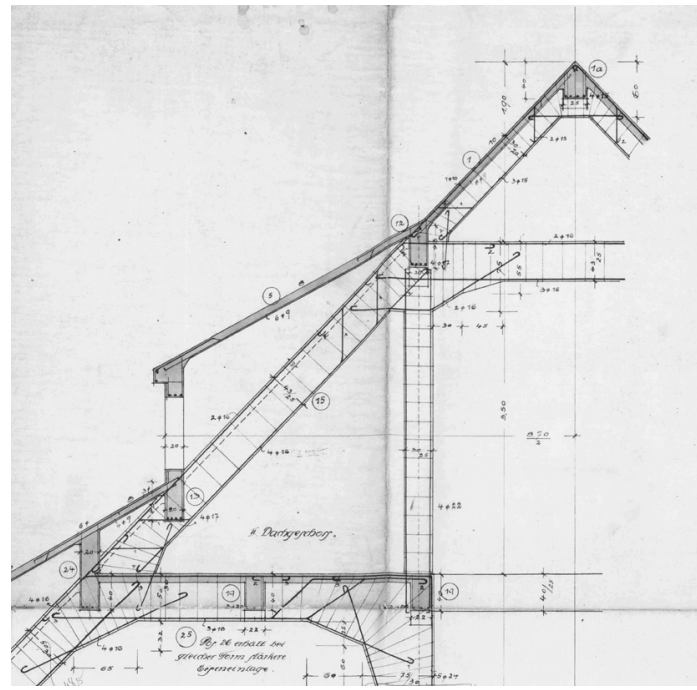

Fig. 12. The reinforcement of the concrete frame of the $6^{\text {th }}$ and $7^{\text {th }}$ floors [12].

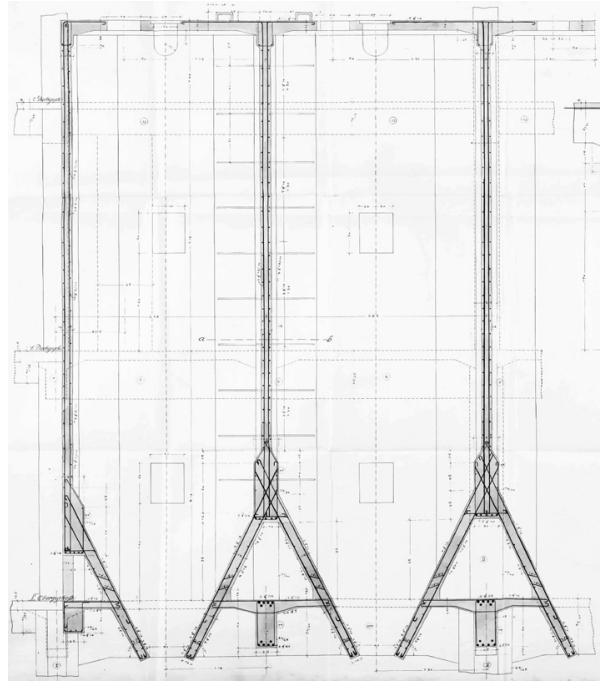

Fig. 13. The reinforcement of the concrete silos for flour [12].

The main structure of the flour warehouse building is 3-bayed, with supporting brick longitudinal walls and two rows of reinforced concrete columns that define the central, narrower communication bay (Fig. 11). The floors are made of reinforced concrete, slabribbed and based on central columns and external walls. Between the $5^{\text {th }}$ and $6^{\text {th }}$ floors of the building, between the elevator shafts, was a battery of 6 concrete silos for flour. The bases of the silos were situated on the floors' main beams (Figs. 9, 11). Precise drawings of the reinforcement disposition in the slabs, beams, attic floor frames (Fig. 12) and also silos (Fig. 13) were found in the archival documentation. These were invaluable in attempts to identify the reinforcements when both making opencasts and using non-destructive testing.

On the ground floor of the connecting building, the supporting structure consists of two two-span, arched reinforced concrete frames (Figs. 14, 15). The main structure above the ground floor is made out of thickened pilasters in the walls, which are connected to each other on the floors with slanted beams, and over the last floor of the building they create a system of reinforced concrete frames with spacing of approx. $3.3 \mathrm{~m}$ (Fig. 14). 


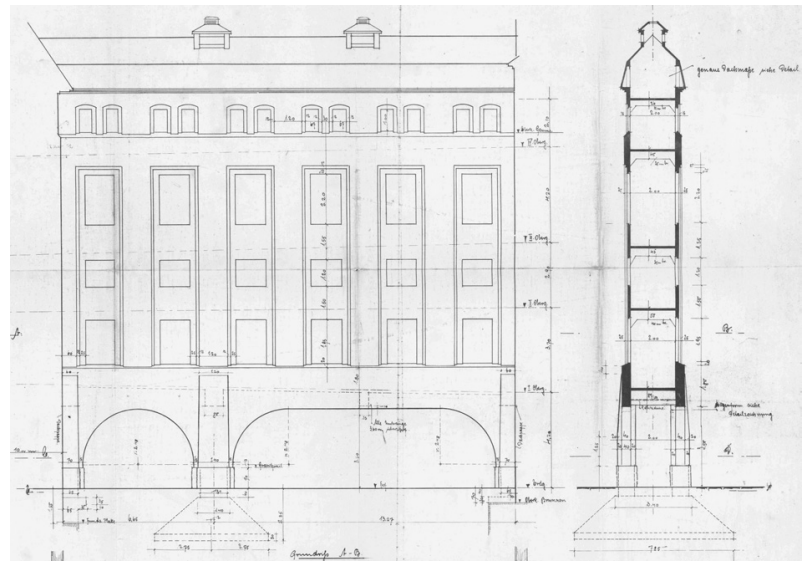

Fig. 14. The archival cross-section of the connecting building [12].

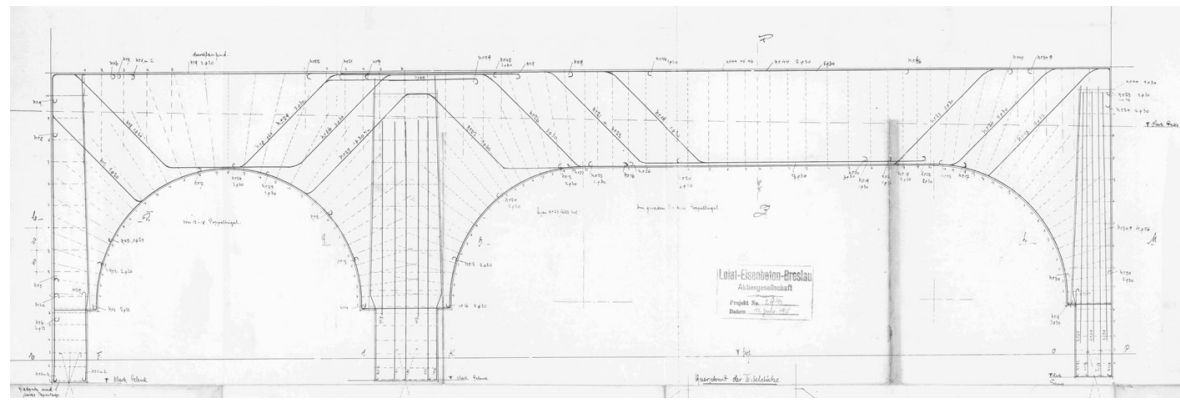

Fig. 15. The reinforcement of the main frame of the connecting building [12].

\subsection{Damage inventory}

Numerous different examples of damage, typical for concrete structures of such an age and history of exploitation, were found during a visual inspection of both buildings. For example, all the floor slabs in the flour warehouse building, as well as roof coverings, have cracks in many places (Fig. 16). Generally, they were caused by the corrosion of reinforcing bars, the large spacing of bars in relation to the small thickness of the slabs and also the lack of top or diagonal reinforcement at the side supports.

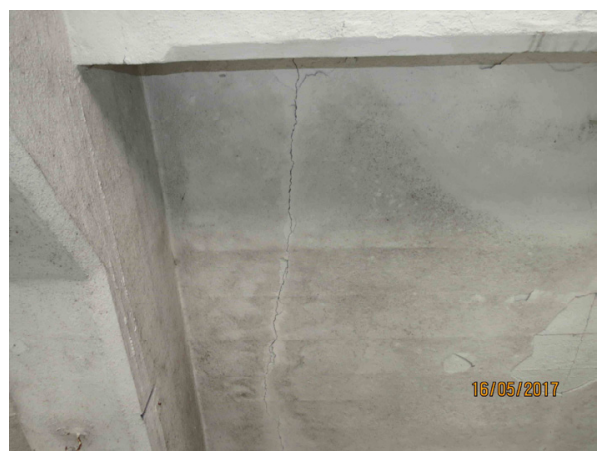

Fig. 16. Cracks in the RC roof slab over the $6^{\text {th }}$ floor in the flour warehouse.

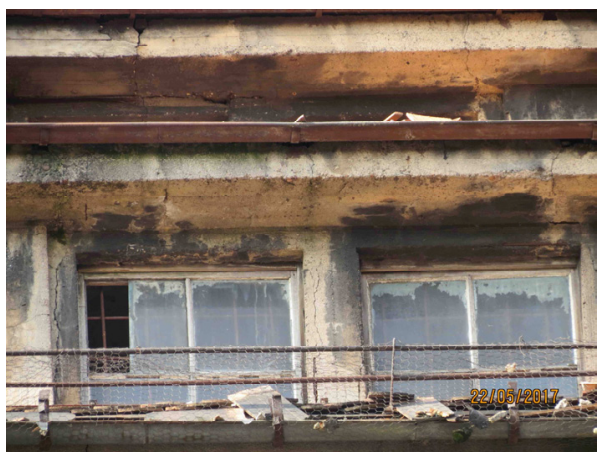

Fig. 17. Corrosion of the outer surface of concrete window frames in the flour warehouse. 


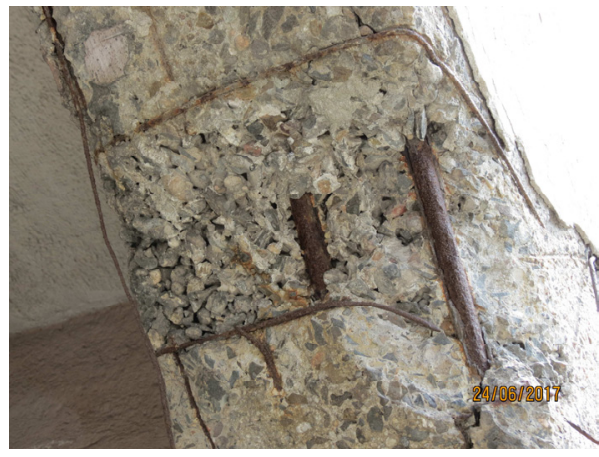

Fig. 18. Concrete destruction in the bearing frame of the connecting building.

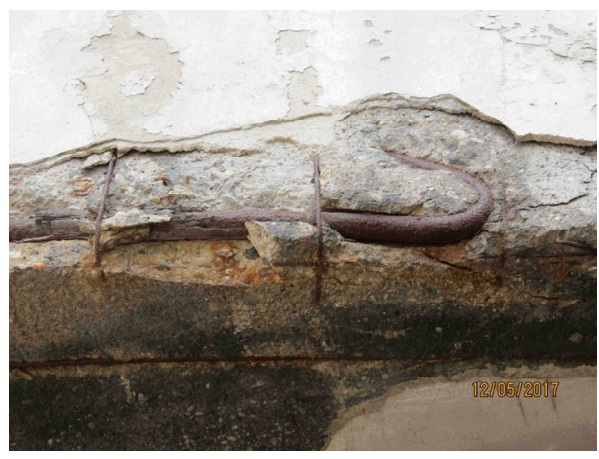

Fig. 19. Concrete and steel corrosion in the bearing frame of the connecting building.

Concrete elements that were exposed to environmental hazards, such as water penetration, freezing or atmospheric pollution, etc., were obviously damaged the most. This damage was found in the flour warehouse's window frames (Fig. 17) on the attic floor and in several parts of the connecting building's frames (Figs. 18, 19).

None of this damage is currently dangerous for the structural safety of the presented buildings, however, repair work will be necessary during the refurbishment process.

\subsection{Material examination}

The results of simple sclerometer tests showed that the reinforced concrete elements in the buildings were made of concrete of very different quality. In these elements, such as the ceilings as well as pillars, concrete from C12/15 to C30/37 was found. The low quality of concrete (especially due to aggregate segregation and a lack of proper compaction) was also confirmed by direct observations carried out during a visual inspection (Fig. 20). On the basis of the sclerometric tests, it was assumed in the control calculations that the concrete in the ceilings and pillars corresponds to at least a class of C16/20.

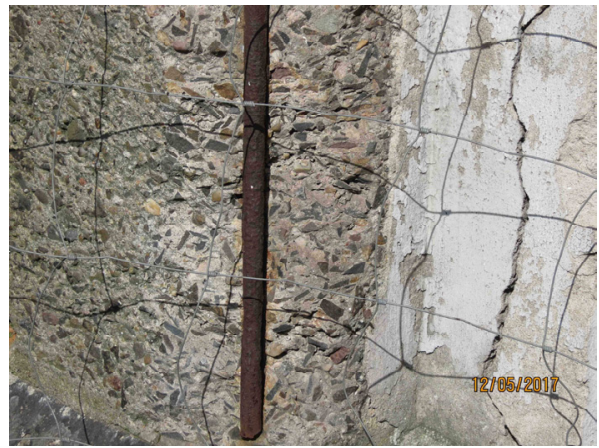

Fig. 20. Concrete structure in the bearing frame of the connecting building.

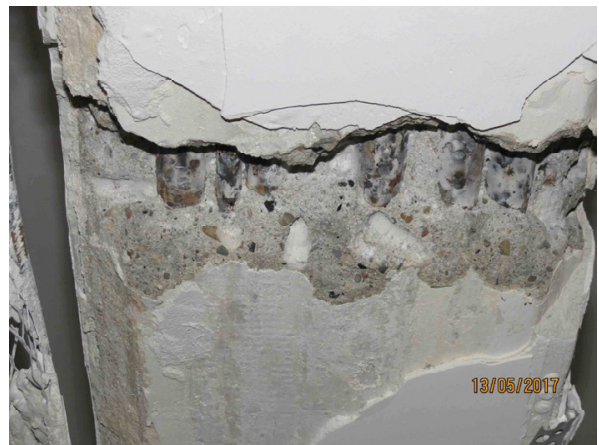

Fig. 21. Reinforcement in the main slab beams of the flour warehouse.

According to studies presented in $[9,10]$, at the beginning of the $20^{\text {th }}$ century cast iron with a tensile strength of $\mathrm{R}_{\mathrm{m}}=370-460 \mathrm{MPa}$ was used as a reinforcement. The results of reinforcing steel tests carried out in recent years in several buildings in Wroclaw confirmed this data [10]. Therefore, to determine the strength of the reinforcing steel used in the assessed objects (Fig. 21), some specimens of reinforcing bars were taken and broken in 
a testing machine. The results of some tests are shown in Figure 22. The following tensile strength results were obtained: $R_{m 1}=445 \mathrm{MPa}, R_{\mathrm{m} 2}=436 \mathrm{MPa}, \mathrm{R}_{\mathrm{m} 3}=394 \mathrm{MPa}, \mathrm{R}_{\mathrm{m} 4}=415$ $\mathrm{MPa}, \mathrm{R}_{\mathrm{m} 5}=397 \mathrm{MPa}, \mathrm{R}_{\mathrm{m} 6}=397 \mathrm{MPa}$. To determine the design yield value, a systematic calculation was used for the same concrete structures. The obtained results were as follows: $\mathrm{R}_{\text {mav }}=414 \mathrm{MPa}, \mathrm{s}=22 \mathrm{MPa}, \mathrm{R}_{\mathrm{G}}=414-1.6422=378 \mathrm{MPa}, \mathrm{f}_{\mathrm{yk}}=0.8378=302 \mathrm{MPa}, \mathrm{f}_{\mathrm{yd}}=$ $302 / 1.5=201 \mathrm{MPa}$. The calculation yield limit $\mathrm{f}_{\mathrm{yd}}=210 \mathrm{MPa}$, corresponding to the Polish AI class of reinforcement steel, was adopted for the verification calculations.

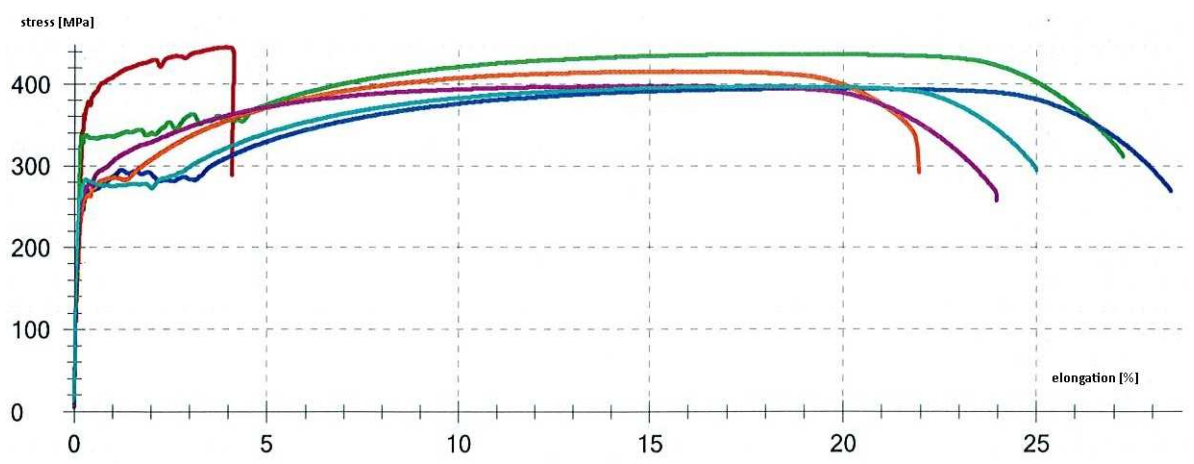

Fig. 22. The results of the reinforcement steel strength examination.

\subsection{Structural modeling verification}

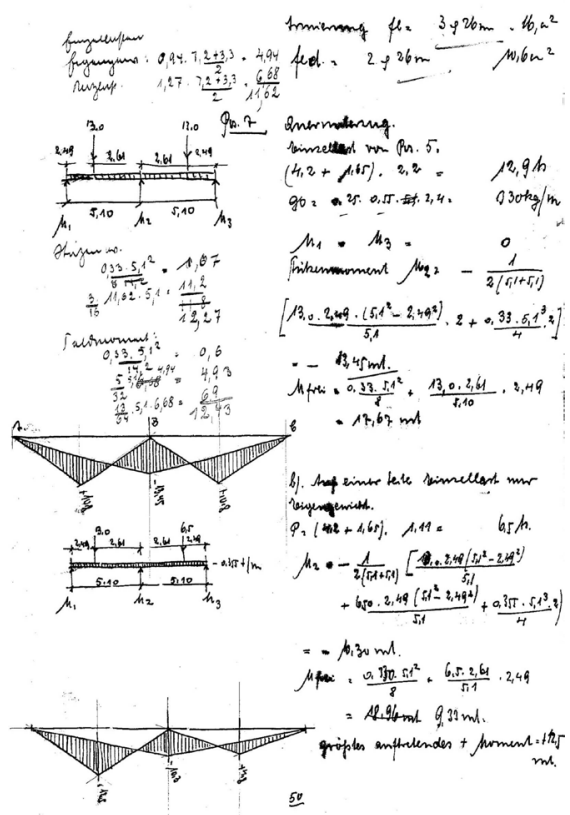

Fig. 23. The archival calculations of the beam in the slab of the flour warehouse [12].

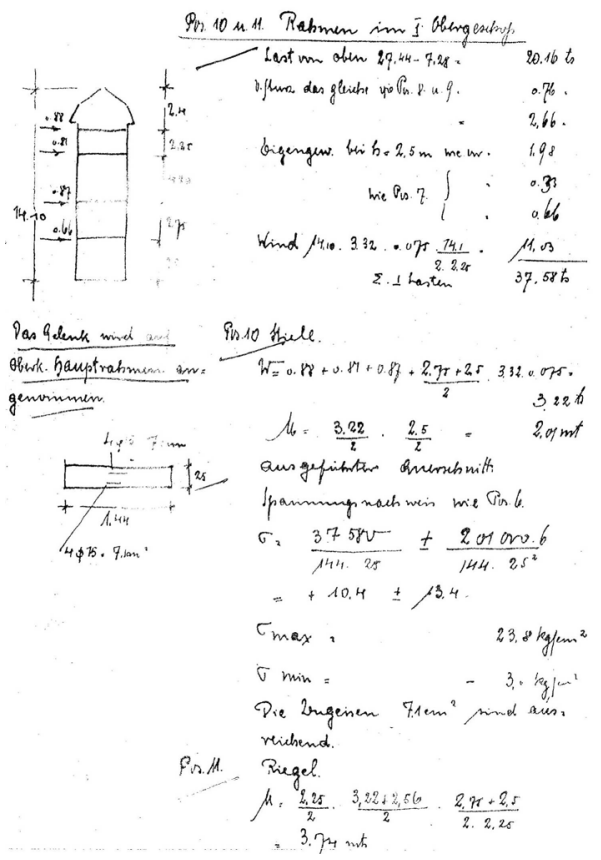

Fig. 24. The archival calculations of the bearing frame of the connecting building [12].

During the assessment it was possible to analyze in the archival documentation the static calculations of the main structural elements of both buildings (Figs. 23, 24) [12]. All reinforced concrete elements were treated as the continuous ones. For this reason, such 
static schemes of the floor plates, the multi-span beams and the frames were used for verification calculations (Fig. 25).

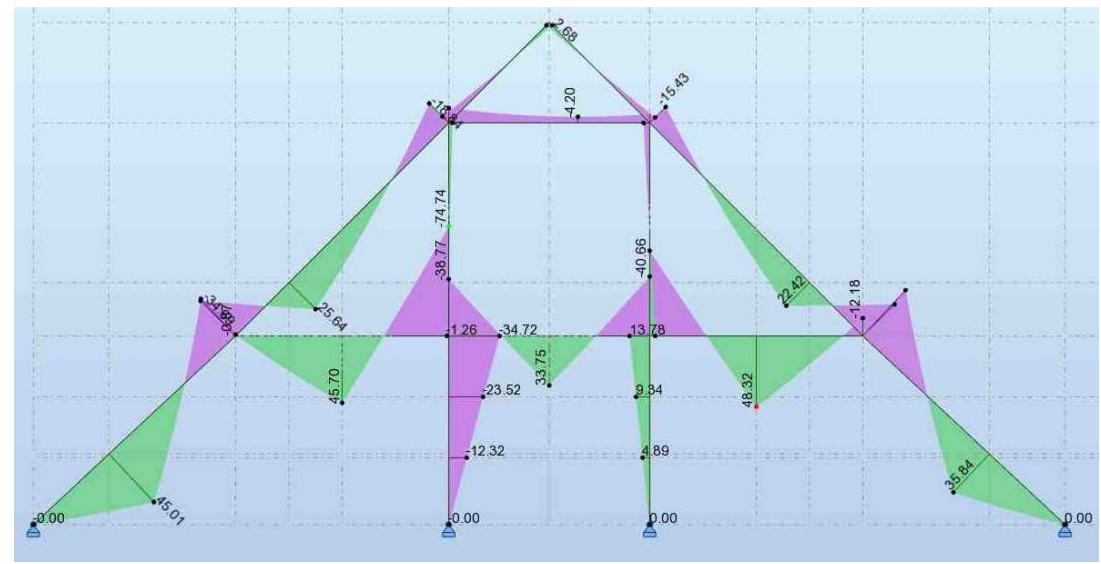

Fig. 25. Exemplary diagram of bending moments for the attic frame of the flour building.

The load capacity of the main structural elements of both buildings for the existing and designed working conditions was checked, assuming that the building will be used for hotel and residential purposes, while the attic will be adapted for service equipment. For all calculation variants it was assumed that the service load of floors will be equal to $2.0 \mathrm{kN} / \mathrm{m}^{2}$ and new dead loads will be applied according to the architectural design concept. The bearing capacity of structural building elements for such loads was verified by calculating necessary reinforcement $\left(A_{n}\right)$ and comparing the results with the existing rebar $\left(A_{e x}\right)$, instead of calculating new permissible loads (Table 1).

Table 1. Comparison of the existing areas of reinforcement with the needed for designed loads.

\begin{tabular}{|c|c|c|c|c|c|c|}
\hline & \multicolumn{7}{|c|}{ Checked structural element } \\
\cline { 2 - 7 } & $\begin{array}{c}1^{\text {st }} \text { floor } \\
\text { slab }\end{array}$ & $\begin{array}{c}1^{\text {st }} \text { floor } \\
\text { beam }\end{array}$ & $\begin{array}{c}4^{\text {th }} \text { floor } \\
\text { slab }\end{array}$ & $\begin{array}{c}4^{\text {th }} \text { floor } \\
\text { beam }\end{array}$ & $\begin{array}{c}\text { attic frame } \\
\text { beam }\end{array}$ & $\begin{array}{c}\text { attic roof } \\
\text { slab }\end{array}$ \\
\hline$A_{\text {ex }}\left[\mathrm{cm}^{2} / \mathrm{m}\right]$ & 5,55 & 19,0 & 2,78 & 19,6 & 11,14 & 3,85 \\
\hline$A_{n}\left[\mathrm{~cm}^{2} / \mathrm{m}\right]$ & 3,44 & 15,3 & 2,50 & 19,5 & 7,33 & 1,86 \\
\hline
\end{tabular}

For all examined structural elements (including foundations), assuming material data according to the chapter 3.3, and static and structural assumptions according to the archival data [12], verified by the inventory, it was demonstrated that the current load-bearing capacities of the checked elements are sufficient to transfer planned dead and service loads designed for new building function.

\section{Conclusions}

On the example of two industrial buildings with a reinforced concrete bearing structure, which belong to the historic bakery complex from the turn of the $20^{\text {th }}$ century, results of the analysis of their technical condition have been presented. The assessment aimed to determine the possibility of the reconstruction and adaptation of these objects for new utility purposes, and in turn to extend their service life while taking into account their historical value. Special emphasis was placed, however, on the analysis of the information 
and data contained in the archival documentation and its comparison to the results of the conducted material examination, static calculations and design procedures.

In both cases of the studied buildings, extensive calculations and drawings were available in the archival documentation, which enabled a very accurate analysis of the bearing capacity of their structural elements to be carried out. Moreover, the data obtained from the material tests and reinforcement trial exposures was also used. These confirmed that old concrete structures sometimes have capacity reserves (despite structural elements with local damage, especially in the case of these directly exposed to the environmental influences). That will allow the design of less invasive renovation works or application of strengthening solutions that respect the engineering industrial heritage of the discussed buildings.

\section{References}

1. P. Berkowski, M. Kosior-Kazberuk, Construction history as a part of assessment of heritage buildings, Proc. Eng. 161, pp. 85-90 (2016).

2. P. Berkowski, G. Dmochowski, Examples of concrete structural elements in early 20th century buildings in Wroclaw (Poland) - case studies, Concrete solutions: 5th International Conference on Concrete Repair, pp. 699-706 (2014).

3. P. Berkowski, M. Kosior-Kazberuk, Historical and structural aspects of the durability and maintenance of a reinforced concrete market hall building from the early 20th century, Concrete solutions: 6th International Conference on Concrete Repair, pp. 335-343 (2016).

4. B. Espion, Y. Rammer, A. Hellebois, M. Provost, Three case studies of construction history applied to the assessment of engineering heritage structures, IABSE Symposium Report, 105 (42), pp. 443-450 (2015).

5. A. Hellebois, A. Launoy, C. Pierre, M. De Lanève, B. Espion, 100-year-old Hennebique concrete, from composition to performance, Construction and Building Materials, 44, pp. 149-160 (2013).

6. R. Brueckner, P. Lambert, Assessment of historic concrete structures, WIT Transactions on the Built Environment, 131, pp. 75-86 (2013).

7. A. Hellebois, O. Germain, B. Espion, Reinforcement assessment in early reinforced concrete constructions, Proc. of the 13th Intl. Conf. Structural Faults \& Repair, Engineering Technics (2010).

8. K. Kirschke, P. Kirschke, Revitalization of the historical bakery buildings the "Mamut" at Sienkiewicza Street 18/22 in Wroclaw, Materiały Budowlane 11, pp. 81-85 (2017) (in Polish).

9. R. Ahnert, K.H. Krause, Typical building structures from 1860 to 1960 . For assessment of existing building substance, vol. 1, Berlin, Verlag für Bauwesen (1991) (in German).

10. K. Czaplinski, Old products from iron alloys, Wroclaw, DWE (2009) (in Polish).

11. Fotopolska.eu.

12. WCBA Wrocław City Building Archive, Museum of Architecture (T2472, T2473). 